OPEN ACCESS

Edited by:

Iñigo Muxika,

Technological Center Expert in Marine and Food Innovation (AZTI), Spain

Reviewed by:

Georgina Valentine Wood, Minderoo Foundation, Australia

Charles Gordon Hannah, Department of Fisheries and Oceans,

Canada

${ }^{*}$ Correspondence: Frederick Whoriskey fwhoriskey@dal.ca

Specialty section:

This article was submitted to Marine Ecosystem Ecology, a section of the journal

Frontiers in Marine Science

Received: 30 June 2021 Accepted: 09 September 2021

Published: 06 October 2021

Citation:

Whoriskey F, Barbier M, Mazur M, Hahn T, Kritzer J and Vallee R (2021)

Maximizing Benefits From Punctual

Ocean Infrastructure: An Ethical

Perspective.

Front. Mar. Sci. 8:733822.

doi: 10.3389/fmars.2021.733822

\section{Maximizing Benefits From Punctual Ocean Infrastructure: An Ethical Perspective}

\author{
Frederick Whoriskey ${ }^{*}$, Michele Barbier², Mackenzie Mazur ${ }^{3}$, Tobias Hahn ${ }^{4}$, \\ Jacob Kritzer ${ }^{5}$ and Richard Vallee ${ }^{6}$ \\ 'Ocean Tracking Network, Dalhousie University, Halifax, NS, Canada, ${ }^{2}$ Institute for Science and Ethics, Nice, France, ${ }^{3}$ Gulf \\ of Maine Research Institute, Portland, ME, United States, ${ }^{4}$ GEOMAR Helmholtz Centre for Ocean Research Kiel, Kiel, \\ Germany, ${ }^{5}$ Northeastern Regional Association of Coastal Ocean Observing Systems, Portsmouth, NH, United States, \\ ${ }^{6}$ InnovaSea, Bedford, NS, Canada
}

Ethics are becoming a component of best practices in ocean science and observing systems, with the research community facing a duty to society to maximize the efficient use and benefits that stem from investments in ocean science/monitoring. Sustained ocean observing systems on issues of global importance are coordinated, internationally sanctioned and making the most out of the resources accorded to them and consequently fulfilling their duty to society. However, globally huge investments are made annually in establishing infrastructure for shorter-term, punctual studies that address targeted as opposed to broad science needs. More could be done to maximize the benefits and impacts of these punctual efforts. Given punctual infrastructure's small and frequently transient nature, connections to enable sharing will probably be done locally, and both potential additional users and owners of the infrastructure will need to be energetic, receptive and flexible. The accommodation of new uses will have to be balanced against any costs of these additional activities, which could pose an ethical dilemma in themselves if they compromise the infrastructure's ability to meet its original intent. However, such adaptive infrastructures may be the most efficient way to provide the resources needed to identify and monitor emerging or new ocean stressors.

Keywords: ethics, ocean, observation, punctual infrastructure, communication

\section{INTRODUCTION}

The launch of the United Nations Decade of Ocean Science for Sustainable Development ("the Decade" marks a period of great hope for a global transformation of humankind's caring for and use of the ocean. Hailed as a once in a lifetime event that will provide the science we need for the ocean we want, the Decade has focused on major ocean themes (e.g., climate change, deoxygenation, marine plastics, acidification/decarbonization) with hopes to make major progress in addressing these critical stressors by its end.

A huge portion of the ocean economy and consequently human impacts on the ocean is driven by local developments within the coastal communities of nation states. Coastal communities have always looked to the ocean for their subsistence needs and socioeconomic well-being. Such communities pursue traditional activities such as fishing and shipping, while actively

\footnotetext{
${ }^{1}$ https://en.unesco.org/ocean-decade
} 
seeking new or "underutilized" opportunities to maintain or grow the benefits they can obtain from the ocean. On their own, many of these activities have minor impact, however, collectively they may negatively impact productive, coastal waters (e.g., McCauley et al., 2015). Ocean observing systems in the broadest sense are our "Eyes on the Ocean" 2 and provide pivotal measures and information to guide the avoidance or mitigation of harmful anthropogenic stressors and protect the social and economic benefits that the ocean provides.

Current sustained ocean observing systems (e.g., Argo floats $^{3}$; WMO drifter buoys $)^{4}$ are well coordinated and conduct offshore, internationally significant work addressing issues such as the Decade challenges. These activities are nationally and internationally endorsed, coordinated and resourced. By contrast, in coastal areas a massive amount of punctual scientific work is underway, some undertaken by national and regional authorities, but with huge contributions from academia, the private sector, governments, non-governmental organizations, and more recently citizen science. Limited efforts have gone into documenting and protocoling the scope of these contributions. Assuming science funding provided to researchers in the academic and institutional sector is primarily directed to punctual (short-term, narrow focus) projects, a sense of the current activity can be developed. In Canada, funding to the academic ocean sector from various agencies was conservatively estimated to average about \$92 M (Can) per year in the 2002/032011/12 period, and the estimate was believed to cover one quarter to one third of total university spending on ocean science (Expert Panel on Ocean Science, 2013). Isensee (2020) provided estimates of academic and institution ocean research spending from 26 countries, with values for individual countries ranging from a few million dollars (US) to nearly $\$ 600 \mathrm{M}$ (US) per year.

Punctual studies especially in the academic sector differ from the previously described coordinated offshore work. Such studies are frequently conducted as independent, varied, short-term and/or geographically limited, coastal projects that address fundamental science issues and are laser focused on meeting the science and reporting needs of the investigation team. Various infrastructures (examples: submerged moorings with oceanographic or other instruments attached), e.g., using commercial lobster trap deployments as infrastructure and placing temperature recorders (Fishermen and Scientists Research Society) $)^{5}$ or acoustic receivers on the traps as per Goulette et al., 2014; instrumented buoys anchored at fixed stations, e.g., Boknis Eck Time Series stations in Eckernförder Bay (southwestern Baltic Sea) ${ }^{6}$; periodic sampling of fixed or variable stations from research, commercial or education vessels) are developed to conduct this work. All of these are highly valuable resources that could utilized for multiple uses if owners of the infrastructure are aware, willing and able to accommodate additional scientific uses and users.

\footnotetext{
${ }^{2} \mathrm{https} / /$ ioos.noaa.gov/communications/eyes-on-the-ocean-ioos-bi-weekly/

${ }^{3}$ https://www.aoml.noaa.gov/phod/argo/

${ }^{4}$ https://www.aoml.noaa.gov/global-drifter-program/

${ }^{5}$ https://obis.org/dataset/68670603-4fca-4b3b-ab33-f50b859e3afc

${ }^{6}$ https://www.bokniseck.de/de
}

\section{THE ETHICAL CHARGE}

Ethics can be defined as "well-founded standards of right and wrong that prescribe what humans ought to do, usually in terms of rights, obligations, benefits to society, fairness, or specific virtues" (Velasquez et al., 2010). In a review of ethics in scientific research, Weinbaum et al. (2019) identified 10 ethical principles common across scientific disciplines: (1) duty to society; (2) beneficence; (3) avoiding conflict of interest; (4) informed consent; (5) integrity; (6) non-discrimination; (7) nonexploitation; (8) privacy and confidentiality; (9) professional competence; (10) professional discipline. We believe that the conduct of ocean science activates a duty to society for researchers because their research is either funded by or providing results of interest to the public.

The sustained ocean monitoring systems under the Global Ocean Observing System (GOOS) encapsulate a number of key attributes. These systems are mission orientated and internationally coordinated. ${ }^{7,8}$ GOOS monitoring has been community driven in its development (e.g., Task Team for an Integrated Framework for Sustained Ocean Observing, 2012), and addresses grand scientific imperatives whose impacts can put human and/or ecosystem welfare globally at risk (one example is GOOS' lead role in monitoring trends in ocean temperature globally). Furthermore, they have the backing and resourcing needed to provide credible and trusted information that informs policy makers and managers (e.g., Muller-Karger et al., 2018; Estes et al., 2021). GOOS also has the communications tools needed to provide explanations to the public so that they understand the significance of the issues being addressed. This work is firmly rooted in the duty to society principle.

By contrast, punctual, fundamental research in coastal areas is curiosity-driven, important, beneficial, and generally ethical, but it is not coordinated in the same way and does not have the longevity that sustained observing systems have. On their own the studies that are underway may not have immediate relevance to current issues, and in the public's eyes may seem of little value. ${ }^{9}$ Alternatively, punctual studies may be focused on critically important but very local practical issues. For example, the siting of a fish farm that could affect local fisheries can become a locally explosive issue but not one with the same scope as the changing ocean heat budget. Accessing field sites provides particular and expensive logistical challenges for all ocean studies, driving up costs. We suggest that this issue poses an ethical charge on researchers to maximize the benefits that flow to the public from the resources invested in putting us to sea.

\section{UNIQUE ADVANTAGES TO PUNCTUAL OBSERVING INFRASTRUCTURES}

The culture of academic and government ocean research differs. To take a Canadian example, Canada's Department of Fisheries

\footnotetext{
${ }^{7}$ https://ioc.unesco.org/node/2

${ }^{8} \mathrm{https} / /$ www.goosocean.org/index.php?option=com_content\&view=article\&id= 272\&Itemid=411

${ }^{9}$ https://www.goldengooseaward.org/01awardees/sea-soy-solution
} 
and Oceans (DFO) is by far the dominant ocean research institution in the country (Expert Panel on Ocean Science, 2013). The Minister who oversees DFO receives a mandate letter identifying clearly defined ocean priorities of the Federal government on which DFO is to focus. ${ }^{10}$ Subjects that are not on the list are addressed when and if time and resources permit. By contrast, academic funding agencies in the country are now asking that a diverse set of criteria be met by the researchers that are requesting funding. There is an expectation, if not an obligation, that in addition to addressing the science of research proposals, that the successful investigators also contribute to the training of future generations of diverse early career professionals, support industry in developing new technologies and economic opportunities, and communicate results of their work to a broad range of stakeholders. This predisposes the researchers to novel collaborations. The ocean infrastructure established for punctual research studies may be particularly beneficial to meet the diverse needs of the multiple and varying sectors in that:

- In being coastal or inshore, such infrastructure is easily accessible enabling frequent trips to the sites to retrieve timely results.

- For many Small and Medium Enterprises (SMEs), the cost of field-testing their new technologies and instrumentation can be a significant burden. Testing on an established, easy-to-access infrastructure at low-to-no cost is highly attractive.

- In collaborating different groups can network and tap into each other's technical and communications capabilities, improving work capabilities and facilitating information exchange about each other's work. Individuals maintaining punctual infrastructures are frequently "site attached" to a particular place in the ocean. While their study foci and the infrastructures used may vary over time, in working within these same areas for extended periods of time, they develop a deep knowledge of local conditions as well as trust relationships with local stakeholders. In meeting the needs of more user groups, punctual research can help to fill knowledge gaps for decision makers, and put punctual research on the high ground with regards to use of public resources.

\section{OBSTACLES AND QUESTIONS}

There are potential costs and risks in enabling the sharing of infrastructure for purposes other than those it was originally intended to serve. Meeting the scientific needs for which the infrastructure was originally established is the paramount ethical responsibility for investigators and also an issue of great concern to funders. Doing so is directly relevant to the duty to society, professional competence and professional discipline principles. Failure to do so because resources were diverted to addressing other topics poses a serious risk of censure of the current and

\footnotetext{
${ }^{10} \mathrm{https} / /$ pm.gc.ca/en/mandate-letters/2019/12/13/minister-fisheries-oceans-
} and-canadian-coast-guard-mandate-letter future activities for the investigators and the funding agency alike. Secondly, taking the lead in communicating the opportunity and organizing the logistics of sharing the infrastructure capabilities is time consuming and can detract from primary research activities. Scientists are career-driven and work in a hierarchy where failures or delays in delivering results can significantly impact careers (Fortunato et al., 2018). Third, there are potential liability risks involved in sharing infrastructure. Defining who bears what risk, especially in terms of damage or loss to equipment that is codeployed, is necessary. Fourth, there will be a limit on how much sharing can occur on any given infrastructure. When demands for co-deployments exceed the capacity of an infrastructure to accept them and still fully support its core mission, some sort of fair and transparent procedure to evaluate which co-deployments are to proceed could be needed. Finally, many investigators are reluctant to participate in research collaborations and/or share data, for complex and varied reasons that depend on factors such as intellectual property issues, whether the person is naturally altruistic and the type of institution in which they work (Nguyen et al., 2017).

\section{FAILURE AND SUCCESS: THE CASE OF THE OCEAN TRACKING NETWORK}

The Ocean Tracking Network (OTN; see Hussey et al., 2015; Iverson et al., 2019) is a global technology, infrastructure and research platform headquartered at Dalhousie University, Halifax, Nova Scotia. Starting in 2008, the OTN began deploying acoustic receivers and oceanographic monitoring equipment in key global ocean locations to document the movements and survival of marine animals carrying electronic tags, and to link both to oceanographic conditions. Annually, OTN deploys approximately 2000 moorings globally. Some of these deployments are semi-permanent, whereas others change from year to year.

OTN has benefited in its work by opportunistically deploying acoustic telemetry equipment on mooring systems established for other purposes. The most expansive of these is the PIRATA (Prediction and Research Moored Array in the Tropical Atlantic) buoy network which spans the Tropical Atlantic Ocean between Africa and Brazil (Bourlès et al., 2019). This has enabled OTN to provide receiver coverage in an area that OTN could not otherwise afford to cover, to the benefit of the international network of scientists who work with the OTN. OTN has been consciously seeking to return this favor by finding opportunities for others to benefit from working with OTN's own moorings. This has met with mixed success.

At certain predictable locations and depths, extended OTN mooring deployments are prone to extensive biofouling. Based on this, OTN anticipated that its moorings and established maintenance schedules providing access (at our expense) could be of considerable interest as test beds to researchers and companies attempting to find new solutions to reduce biofouling. Such solutions would also be of direct benefit to the OTN by reducing the amount of future labor needed to remove biofouling. However, to date none of the outreach has generated 
interest in using our infrastructure to study new methods of biofouling control.

By contrast, this biofouling on these moorings proved to be of great interest to another community investigating deepsea sponge grounds. OTN learned of the European Horizon 2020 SponGES project ${ }^{11}$ through an early morning interview on a local radio station in Nova Scotia. The interview described the challenges being faced by Canadian members of SponGES from the DFO as they worked to obtain samples of glass sponges (Vazella pourtalesii) off Halifax. This was despite having access to a large research vessel, and the highly capable ROPOS (Remotely Operated Platform for Ocean Science) remotely operated vehicle. ${ }^{12}$ Fortuitously, a line of OTN receivers had been placed through the target sponge grounds. OTN worked with the SponGES team and brought some of these to the surface to see if the sponges had colonized them. Hundreds were present, providing unique insights into settlement patterns, growth rates, and reproduction of the species. The sponges also arrived at the surface in great condition making it feasible to transport them alive to the laboratory where controlled experiments could be undertaken. Additional tissue samples were distributed among the investigators of the network for genetics, microbiotics and marine biopharmaceutical research, with some work published (e.g., Busch et al., 2020) and much still ongoing.

\section{MAKING CONNECTIONS HAPPEN}

Small scale, diffuse, anthropogenic ocean impacts such as municipal waste discharges or the impacts of a fish farm will typically manifest themselves at local as opposed to global scales. The practical significance of this is that local people will first identify stressors at this scale. A corollary to this is locally networked scientists will be the first to be sought out to try and help with such problems. Thus, opportunities to connect potential infrastructure capacities with people who seek to address the issues will need to occur at the local level. Probably most of this will be done by word of mouth, and for this to be effective both the owners of the infrastructure and the research teams seeking access to it will need to be energetic, receptive, and flexible.

The groundwork that needs to be laid to make it probable that timely connections occur is in communication with local groups about the available research infrastructure and about the expertise of local investigators. When receptive minds learn about the infrastructure and expertise, connections will form. The OTN SponGES link mentioned previously is a good example of this. While many connections may occur informally, we also have examples of sophisticated and directed networks that could serve as models. Otlet ${ }^{13}$ was formed to provide a global open-access platform to share and source marine biological samples. It was developed to address the waste of time, money and world class research opportunities that occurs when haphazard (informal)

\footnotetext{
${ }^{11}$ https://spongis.org/the-sponges-project/

${ }^{12}$ https://www.ropos.com/

${ }^{13}$ https://otlet.io/
}

means are used to try and establish scientific collaborations. Otlet is a data system that matches those seeking samples with those who have them. Their system currently catalogs 22,000 samples from 330 species and has 645 scientists engaged.

Regional ocean observing associations also have the potential to foster connections. In both the United States and Canada, associations such as the Northeastern Regional Association of Coastal Ocean Observing Systems (NERACOOS), ${ }^{14}$ the St. Lawrence Global Observatory ${ }^{15}$ and the Canadian Integrated Ocean Observing System-Atlantic ${ }^{16}$ are established or nascent, have talented, permanent staff, and draw on regional investigators and investigations. In their instigation and networking of the ocean observation efforts underway in their area of operations, these regional organizations also network the investigators who collect the data. Through their regular network meetings, and their communications channels and stable staff that maintain institutional memory, they could serve as a valuable vehicle to broker connections of existing infrastructure with new opportunities either directly through targeted matchmaking, or indirectly through conversations.

Key considerations for tagging along on an existing infrastructure is that the equipment be robust, as small as possible, be easily mountable, and have its own power source and data storage capabilities. While it might be possible to integrate new instrumentation into the power supplies and communications linkages of existing moorings, this is typically time consuming, expensive and troublesome and reduces the enthusiasm for co-deployments.

What should be avoided is draconian attempts to force connections. Requiring scientists to make links to areas where they may have no expertise and punishing them if they do not is a recipe for friction and stifles collaboration.

\section{DISCUSSION}

Despite the opportunities and undoubted advances that will offered to us by the Decade, when the Decade is done the ocean will most probably still be under stress from human activities (Donovan et al., 2021; Sydeman et al., 2021). We need to keep sight of how we can use the opportunities offered by the Decade to position ourselves for what comes after. In other words, the Decade is not only an opportunity to fundamentally change conditions in the ocean and ocean-dependent communities, but also in how we observe, study and interact with the ocean going forward. For the future professionals we are training, the longterm vision for the Decade's "once in a lifetime opportunity" must also mean positioning ocean science at a new level of networking and efficiency. This will provide the next generation of practitioners with the tools needed to cope with the impacts of the stressors that will endure beyond the Decade. At the same time, transforming the conduct of ocean science will enable more effective responses to challenges that arise as

\footnotetext{
${ }^{14} \mathrm{http}: / /$ www.neracoos.org/about

${ }^{15}$ https://www.ogsl.ca/en/about-slgo/

${ }^{16}$ https://cioosatlantic.ca/about/system
} 
advancing technology fosters new economic developments and impacts on the ocean.

Established, global, sustained observing systems address known, critically important issues and have been embraced internationally. However, these systems measure only some of humanity's impacts on the ocean and we turn to local, punctual studies to provide knowledge of other stressors and the condition of the coastal and open ocean. A great deal is invested in these studies and given the importance and rapid pace of ocean change it is an ethical imperative to derive the maximum benefits from as many investments as possible that we make in ocean science infrastructure.

While few would disagree that finding a way to get more out of the investments we are already making is a win for all, the challenge for the smaller scale, punctual, independent, less coordinated infrastructure initiatives is how to incorporate additional users in a way that is not punishing and prohibitively draining for those who established the infrastructure. Making things as simple as possible is one key, but unlike for global efforts the smaller-scale and highly varied nature of punctual infrastructures means opportunities for co-deployments will probably arise at the grass-roots level. This makes the good will of the participants and awareness of possibilities the key to success. The first step is for researchers to think about possibilities for and the benefits of extending access to their infrastructure to others. Busy scientists focus on their own programs, not what we might do to assist others. However, many scientists are altruistic, and should the process of designing field studies and setting infrastructures ask not only how these assets support the primary task but also how they could be used by others, people will become aware of and open to collaborative opportunities on a more widespread basis. Next, those willing to collaborate need time, additional financial support, and diffusion mechanisms to communicate the opportunities/assets they have to offer. Funder mandates that move in these directions would be powerful, as long as those mandates are backed up by resources and do not place unreasonable demand on research teams.

Achieving these objectives is a communications issue, and could be addressed through word of mouth, email lists, networks such as the OTN, xylosystems.org or data through public access data systems (e.g., Reef Life Survey, Atlas of Living Australia, Oceans Network Canada, OTN). Social media networks or websites related to particular sampling locations or infrastructures similar to that produced by the

\section{REFERENCES}

Bourlès, B., Araujo, M., McPhaden, M. J., Brandt, P., Foltz, G. R., Lumpkin, R., et al. (2019). PIRATA: a sustained observing system for tropical Atlantic climate research and forecasting. Earth Space Sci. 6, 577-616. doi: 10.1029/ 2018EA000428

Busch, K., Beazley, E., Kenchington, E., Whoriskey, F., Slaby, B. M., and Hentschel, U. (2020). Microbial diversity of the glass sponge Vazella pourtalesii in response to anthropogenic activities. Conserv. Genet. 21, 1001-1010. doi: 10.1007/ s10592-020-01305-2

Donovan, M. K., Burkeile, E. E., Kratochwill, C., Shlensinger, T., Sully, S., Oliver, T. A., et al. (2021). Local conditions magnify coral loss after marine heatwaves. Science 372, 977-980. doi: 10.1126/science.abd9464
Otlet network could be created, highlighting collaborative opportunities and making contact with potential partners. Even something as simple as including an "aside" slide in conference and seminar presentations of existing facilities and asking if anyone could make use of them could have big impacts. Once collaborative possibilities are identified, it is likely that each will be highly unique. Researchers will have to assess their feasibility and desirability, based on potential benefits and costs. In many if not most cases, the pull of the benefits will outweigh the costs both in terms of public good, but also for individual careers in terms of contribution to public good, networking, opportunities to contribute to multi-disciplinary studies, learning new skills, and potential co-authorships in scientific publications (Nguyen et al., 2017; Fortunato et al., 2018). Persistent communication will be needed to maintain this level awareness over time, however, every success puts us a bit farther ahead in ocean monitoring toward a sustaining future of humankind.

\section{DATA AVAILABILITY STATEMENT}

The original contributions presented in the study are included in the article/supplementary material, further inquiries can be directed to the corresponding author/s.

\section{AUTHOR CONTRIBUTIONS}

$\mathrm{MB}$ organized the ethics symposium at which this work originated. FW provided the original concept for the piece. All authors contributed ideas and text for this Perspectives piece.

\section{ACKNOWLEDGMENTS}

This manuscript stems from a presentation at the Evolving and Sustaining Ocean Best Practices Workshop IV, September 2020 within the Ethics and Best Practices for Ocean Observing and Applications session organized by $\mathrm{MB}$ and the Working Group on Ethics and Best Practices. The co-authors all thank $\mathrm{MB}$ for challenging ourselves to look at our work from a different perspective. The manuscript benefited greatly from the thoughtful and thorough comments of two reviewers.

Estes, M. Jr., Anderson, C., Appeltans, W., Bax, N., Bednaršek, N., Canonico, G., et al. (2021). Enhanced monitoring of life in the sea is a critical component of conservation management and sustainable economic growth. Mar. Policy 132:104699. doi: 10.1016/j.marpol.2021.104699

Expert Panel on Ocean Science (2013). Ocean Science in Canada: Meeting the Challenge, Seizing the Opportunity. Canadian Council of Academies. Available online at: https://cca-reports.ca/wp-content/uploads/2018/10/ oceans_fullreporten.pdf (accessed September 23, 2021).

Fortunato, S., Bergstrom, C. T., Börner, K., Evans, J. S., Helbring, D., Milojević, S., et al. (2018). Science of science. Science 359:eaa00185. doi: 10.1126/science. aao0185

Goulette, G., Hawkes, J., Kocik, J., Manning, J. P., Music, P., Wallinga, J., et al. (2014). Opportunistic acoustic telemetry platforms: benefits of 
collaboration in the Gulf of Maine. Fisheries 39, 441-450. doi: 10.1080/ 03632415.2014 .943740

Hussey, N. E., Kessel, A., Cooke, S. J., Cowley, P. D., Fisk, A. T., Harcourt, R. G., et al. (2015). Aquatic animal telemetry: a panoramic window into the underwater world. Science 348:1255642. doi: 10.1126/science. 1255642

Isensee, K. (ed.) (2020). Global Ocean Science Report 2020: Charting capacity for ocean sustainability. Intergovernmental Ocean Commission, United Nations Education, Scientific and Cultural Organization. Available online at: https:// unesdoc.unesco.org/ark:/48223/pf0000375147 (accessed September 23, 2021).

Iverson, S. J., Fisk, A. T., Hinch, S. G., Mills-Flemming, J., Cooke, S. J., and Whoriskey, F. G. (2019). The Ocean Tracking Network: advancing frontiers in aquatic science and management. Can. J. Fish. Aquat. Sci. 76, 1041-1051. doi: 10.1139/cjfas-2018-0481

McCauley, D. J., Pinsky, M. L., Palumbi, S. R., Estes, J. A., Joyce, F. H., and Warner, R. R. (2015). Marine defaunation: animal loss in the global ocean. Science 347:1255641. doi: 10.1126/science.1255641

Muller-Karger, F. E., Miloslavich, P., Bax, N., Simmons, S., Costello, M. J., Pinto, I. S., et al. (2018). Advancing marine biological observations and data requirements of the complementary Essential Ocean Variables (EOVs) and Essential Biodiversity Variables (EBVs) frameworks. Front. Mar. Sci. 5:211. doi: 10.3389/fmars.2018.00211

Nguyen, V., Brooks, J. L., Young, N., Lennox, R., Haddaway, N., Whoriskey, F. G., et al. (2017). To share or not to share in the emerging era of big data: perspectives from fish telemetry researchers on data sharing. Can. J. Fish. Aquat. Sci. 74, 1260-1274. doi: 10.1139/cjfas-20160261

Sydeman, W. J., Schoeman, D. S., Thompson, S. A., Hoover, B. A., Garcia-Reyes, M., Daunt, F., et al. (2021). Hemispheric asymmetry in ocean change and the productivity of ecosystem sentinels. Science 372, 980-983. doi: 10.1126/science. abf1772
Task Team for an Integrated Framework for Sustained Ocean Observing (2012). A Framework for Ocean Observing. Paris: UNESCO. doi: 10.5270/OceanObs09FOO

Velasquez, M., Andre, C., Shanks, S. J., and Meyer, M. (2010). What is ethics? J. Issues in Ethics 1, 623-635. Available onlei at: http://ibccatl.weebly.com/ uploads/9/2/2/4/9224085/what_is_ethics.pdf

Weinbaum, C., Landree, E., Blumenthal, M. S., Piquado, T., and Gutierrez, C. I. (2019). Ethics in Scientific Research: An Examination of Ethical Principles and Emerging Topics. (Santa Monica, CA: Rand Corporation), 118. doi: 10.7249/ RR2912

Conflict of Interest: RV was employed by Innovasea Systems Inc.

The remaining authors declare that the research was conducted in the absence of any commercial or financial relationships that could be construed as a potential conflict of interest.

Publisher's Note: All claims expressed in this article are solely those of the authors and do not necessarily represent those of their affiliated organizations, or those of the publisher, the editors and the reviewers. Any product that may be evaluated in this article, or claim that may be made by its manufacturer, is not guaranteed or endorsed by the publisher.

Copyright (C) 2021 Whoriskey, Barbier, Mazur, Hahn, Kritzer and Vallee. This is an open-access article distributed under the terms of the Creative Commons Attribution License (CC BY). The use, distribution or reproduction in other forums is permitted, provided the original author(s) and the copyright owner(s) are credited and that the original publication in this journal is cited, in accordance with accepted academic practice. No use, distribution or reproduction is permitted which does not comply with these terms. 